\title{
High Expression of hsa_circRNA_001387 in Nasopharyngeal Carcinoma and the Effect on Efficacy of Radiotherapy
}

This article was published in the following Dove Press journal: OncoTargets and Therapy

\author{
Mingxia Shuai' \\ Liang Huang ${ }^{2}$ \\ 'Department of Otolaryngology Head \\ and Neck Surgery, Xiangya Hospital, \\ Central South University, Changsha, \\ Hunan 410008, People's Republic of \\ China; ${ }^{2}$ Department of Urology, The First \\ Affiliated Hospital of Nanchang \\ University, Nanchang, Jiangxi, People's \\ Republic of China
}

Background: Nasopharyngeal carcinoma (NPC) is one of the most difficult cancers to be detected and treated. Hunting for novel cancer-specific biomarkers for NPC patients is helpful for timely diagnosis and clinical treatment of NPC.

Methods: In this study, high-throughput circRNA sequencing was used to screen the circRNAs with expression variation in NPC patients. qRT-PCR was used to detect the expression level of hsa_circRNA_001387 in the cancer tissues from 100 surgical patients, the peripheral blood samples from 100 radiotherapy patients and NPC cell lines. Based on clinical data of the patients, the relationship between hsa_circRNA_001387 and radiotherapy as well as antibody to Epstein-Barr (EB) virus was investigated. The use of this circRNA as a biomarker for NPC was also discussed.

Results: Expression of hsa_circRNA_001387 was significantly increased in the tumor tissues of NPC surgical patients, in the peripheral blood samples of NPC radiotherapy patients and in the NPC cell lines $(\mathrm{P}<0.01)$. Expression of hsa_circRNA_001387 was significantly elevated in patients with well-differentiated tumors, lymph node metastasis and distant metastases, stage III-IV, positive EB virus, or family history of NPC. hsa_circRNA_001387 was closely associated with the prognosis of the patients. The overall survival and progression-free survival were shorter in patients with high expression. Through univariate and multivariate analyses, it was found that hsa_circRNA_001387 was considered as an independent factor for the prognosis of NPC patients.

Conclusion: This study reported for the first time that expression of hsa_circRNA_001387 is significantly upregulated, and it was also indicated that hsa_circRNA_001387 can be used as a novel biomarker for NPC.

Keywords: NPC, circRNA, hsa_circRNA_001387, biomarker, radiotherapy

\section{Background}

Nasopharyngeal carcinoma (NPC) is a common malignant head and neck cancer in China. NPC is characterized by geographic regional aggregation and commonly occurs in the southern regions of China, ${ }^{1}$ particularly in Guangdong and Guangxi Province, with an incidence of two cases per 1000 people. ${ }^{2}$ Furthermore, the incidence of NPC varies in ethics, countries and regions. NPC is characterized by high malignancy, high incidence of metastasis, early metastasis, and lack of remarkable specific symptoms in the early phase. Most NPC patients do not visit the clinics until the mid-late stage, significantly decreasing the 5-year survival rate. $^{3,4}$ Therefore, early diagnosis and treatment are the effective ways to improve the life quality of NPC patients. ${ }^{5}$ Reoccurrence and metastasis are the key factors
Correspondence: Liang Huang Department of Urology, The First Affiliated Hospital of Nanchang University, Nanchang, Jiangxi, People's Republic of China

Email xy_urology@I26.com 
that affect prognosis. At present, there are no specific markers to predict the prognosis of NPC patients. Thus, it is urgent to develop novel markers with high sensitivity and specificity for the prognosis of NPC patients.

Different from linear RNAs, circRNAs exist in the body with a closed-loop structure, stably express in a variety of body fluid and exhibit high tissue specificity and cellular specificity. ${ }^{6}$ In recent years, with the rapid development of high-throughput sequencing and bioinformatics, circRNA has been shown to be highly expressed in multiple diseases, especially in tumors. Specific expression of circRNA has been reported in various types of tumor tissues, which is shown to play an important role in tumorigenesis and development, such as gastric cancer, ${ }^{7}$ liver cancer, ${ }^{8}$ breast cancer, ${ }^{9}$ colon cancer, ${ }^{10}$ and prostate cancer. ${ }^{11}$ These findings indicate that circRNA may become a novel diagnostic biomarker and therapeutic target for cancers, which has important potential clinical value for early diagnosis of tumors and improvement of life quality of patients. ${ }^{12}$ Despite the extensive studies of circRNA in tumors, there have been few researches in NPC. The current research has been focused on the radiotherapy of NPC. Therefore, further in-depth study of the effect of circRNA expression on NPC and pathogenesis is beneficial to provide a preliminary clinical basis for the treatment of NPC. In this study, hsa_circRNA_001387 was found highly expressed in NPC and closely associated with the occurrence and development of NPC, providing important clinical value.

\section{Materials and Methods}

\section{Sampling and Clinical Data}

During 2016-2019, cancerous tissues and paracancerous tissues ( $>5 \mathrm{~cm}$ from the border of the tumor) from 100 NPC patients who underwent surgical treatment were collected from the Department of Otolaryngology-Head and Neck Surgery of our hospital. None of these patients received radiotherapy prior to surgery. In addition, the peripheral blood samples, prior to and after radiotherapy, were collected from 100 NPC patients who received radiotherapy during the same period. These NPC patients were grouped into radio-resistant patients and radiosensitive patients based on their responses to radiotherapy, and the peripheral blood samples were collected again. Radio-resistance was defined when the disease was still present after 6 weeks following radiotherapy and recurred after 2 months. Radio-sensitivity was defined when no local lesion was present after 6 weeks following radiotherapy and no recurrence within 2 months. The basic information of the patients was collected through an electronic data capture system, including age, gender, tumor size, TNM staging, lymphatic metastasis, tumor differentiation, Epstein-Barr (EB) virus, etc. Tumor size was calculated using the longest diameter detected on computed tomography (CT) scan. Magnetic resonance imaging (MRI) and CT were used in the diagnosis of lymphatic metastasis and evaluation of tumor difference, respectively. All tissue samples were stored at $-80^{\circ} \mathrm{C}$ after collection.

\section{Cell Culture}

Normal nasopharyngeal epithelial cells NP69 and NPC cell lines (HK-1, C666-1, 5-8F, and SUNE-1) were purchased from the Cell Bank of Chinese Academy of Sciences (Shanghai). All the cells were cultured in the 1640 medium (HyClone, Logan, UT, USA) containing $10 \%$ fetal bovine serum. The cell culture was placed in an incubator at $37^{\circ} \mathrm{C}$ with $5 \%$ carbon dioxide. Cells in logarithmic growth phase were used in the experiments.

\section{RNA Extraction}

RNA was extracted from tumor tissues and adjacent tissues, as well as from peripheral blood samples, following the instruction of the TRIzol kit (Invitrogen, USA). RNA quantity and quality were detected by spectrophotometry with the absorbance at 260 and $280 \mathrm{~nm}$. The linear RNA was degraded from the total RNA by RNaseR (EPicentre, USA) and the remaining circRNA was amplified and transcribed into fluorescent cRNA.

\section{circRNA Sequencing}

RNaseR (EPicentre, USA) was used to degrade linear RNA. The remaining circRNA was amplified and transcribed into fluorescent cRNA. The labeled circRNA hybrid was placed on Arraystar Human circRNA Array V2 (8x15K, Arraystar). The Agilent Scanner G2505C was used to scan the chips. Images were analyzed by Agilent Feature Extraction software (version 11.0.1.1). circRNA data were analyzed by GeneSPring 13.0 (Agilent) software. circRNA with expression variation was determined when the change was more than 2.0 folds and $\mathrm{P}$ value $<0.05$.

\section{Confirmation by qRT-PCR}

SuPerScriPt Reverse TranscriPtase (Invitrogen, USA) was used to reversely transcribe RNA into cDNA. ViiA 7 Real-time PCR System (APPlied Biosystems) was used for the real-time qRT-PCR (Arraystar) detection. Each reaction system was $10 \mu \mathrm{L}$, containing $5 \mu \mathrm{L} 2 \times$ MasterMix, $1 \mu \mathrm{L}$ PCRspecific primer $\mathrm{F} / \mathrm{R}$, and $2 \mu \mathrm{L} \mathrm{cDNA}$. The reaction system was 
Table I The Primer of three circRNAs Choose to Validate by qRTPCR

\begin{tabular}{|l|l|}
\hline circRNA & Primer \\
\hline hsa_circRNA_001082 & $\begin{array}{l}\text { F:5' AGTGGAACCGGATATTTAAG 3' } \\
\text { R:5' TACAATGGATTAATTTATTT 3' }\end{array}$ \\
\hline hsa_circRNA_003956 & $\begin{array}{l}\text { F:5' CTCATTAGCATGGGATCCAACG 3' } \\
\text { R:5' ACAGTAAGTACAGGTGATTTAC 3' }\end{array}$ \\
\hline hsa_circRNA_001387 & $\begin{array}{l}\text { F:5' CTCAGGACGGACAAGCACAG 3' } \\
\text { R:5' TCTTCGGAAGTGTTCTAAGA 3' }\end{array}$ \\
\hline 3-Actin (human) & $\begin{array}{l}\text { F:5' GTGGCCGAGGACTTTGATTG3' } \\
\text { R:5'CCTGTAACAACGCATCTCATATT3' }\end{array}$ \\
\hline
\end{tabular}

added to the microwells of the PCR plate and the PCR reaction was performed. $\beta$-actin expression was used as a control for $\mathrm{qPCR}$, and the $\Delta \mathrm{Ct}$ value was used to reflect the circRNA expression level. All primer sequences in this paper were designed by primer 5 and synthesized by Shanghai Biotech. The gene primers are shown in Table 1.

\section{Statistical Analysis}

SPSS20.0 was used for statistical analysis of the data, and the data were expressed by mean \pm standard deviation. $t$-test was used to compare the mean values between two groups and the ANOVA test was used to compare the mean values of multiple groups. The receiver operating curve (ROC) was plotted. When AUC equaled to 0.5, circRNA had no diagnostic value. Kaplan-Meier survival curve was plotted. Log-rank analysis was used to determine the difference in survival rates between patients with high expression of circRNA and those with low expression. $\mathrm{P}<0.05$ indicated a significant difference.

\section{Results}

\section{Selection and Confirmation of circRNA}

The high-throughput circRNA microarray was used to detect the expression of circRNAs in the cancer tissues and tissues adjacent to tumors (control group) from 3 NPC patients. The results showed that 183 circRNAs exhibited expression variation (fold change $>2$ ). Figure $1 \mathrm{~A}$ shows the circRNAs with significant expression variation, including 50 up-regulated and 15 down-regulated circRNAs. Three circRNAs with the most significant variation in expression were selected (see Table 2 for details of circRNAs) for qRT-PCR confirmation (27 cases). The results are shown in Figure 1B. hsa_circRNA_001387 exhibited the most significant up-regulation, and its expression level was significantly higher than that of the control group.

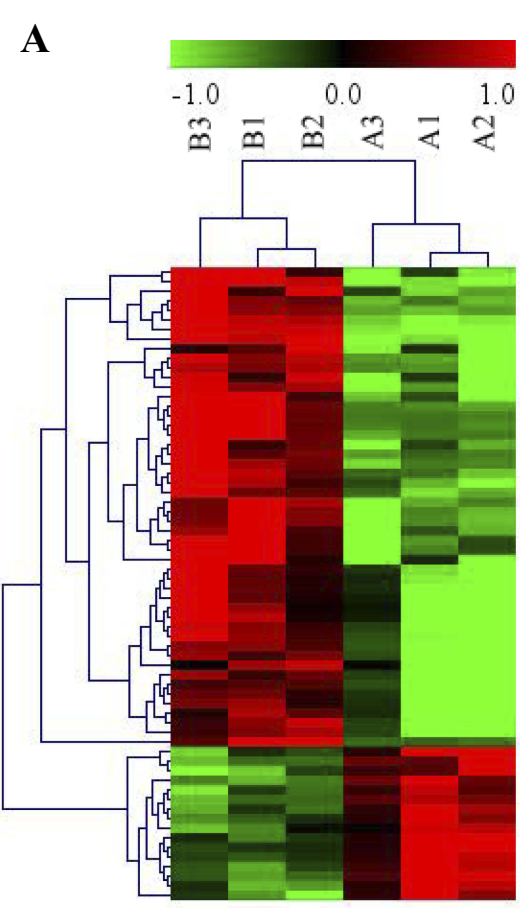

B

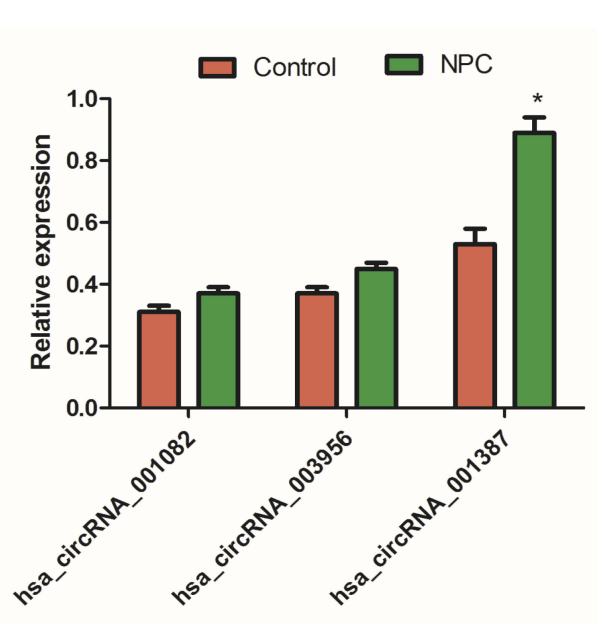

Figure I Selection and detection of circRNA expression variance. (A) shows 50 circRNA with the most significant expression variance. Red indicates high expression while green shows low expression. AI, A2 and A3 are control groups. BI, B2 and B3 are NPC groups. The first 50 are high expression and the bottom I5 are low expression. (B) shows the $\mathrm{qRT}-\mathrm{PCR}$ results of three circRNAs. $* \mathrm{P}<0.05$, compared with control group. All experiments were repeated three times. 
Table 2 The Basic Information of three circRNAs Choose to Validate by qRT-PCR

\begin{tabular}{|c|c|c|c|c|c|c|c|}
\hline circRNA & Alias & Chrom & circRNA Type & FC & Regulation & $\begin{array}{l}\text { Gene } \\
\text { Symbol }\end{array}$ & $P$ value \\
\hline hsa_circRNA_00I082 & hsa_circ_0001082 & Chr8 & Exonic & 3.07 & $U_{p}$ & PCMTDI & 0.03 \\
\hline hsa_circRNA_003956 & hsa_circ_0003956 & Chr3 & Exonic & 3.51 & $U_{p}$ & RNFI3 & 0.02 \\
\hline hsa_circRNA_00|387 & hsa_circ_0001387 & Chr4 & Exonic & 4.30 & $U_{p}$ & WHSCI & 0.04 \\
\hline
\end{tabular}

Abbreviation: FC, fold change.

High Expression of hsa_circRNA_00I387 in NPC Patients and NPC Cell Lines

To further confirm the results of qRT-PCR, the expression of hsa_circRNA_001387 was detected in the tumor tissues and tissues adjacent to tumors from 70 NPC patients (Figure 2A). Consistent with the aforementioned qRT-PCR results, the results showed that the expression was significantly higher in tumor tissues than in the tissues adjacent to tumors. This indicated that with the stable expression in the patients, hsa_circRNA_001387 can be used as a marker for NPC. In addition, hsa_circRNA_001387 expression was also found upregulated in tumors at more advanced stages (Figure 2B). At the same time, expression of hsa_circRNA_001387 was also detected in NK69, HK-1, C666-1, 5-8F and SUNE-1 (Figure 2C). The results showed that the expression of
hsa_circRNA_001387 in HK-1, C666-1, 5-8F and SUNE-1 was significantly higher than that in NP69.

\section{hsa_circRNA_00I387 Was Closely Associated with Radiotherapy in NPC \\ Patients}

Radiotherapy is currently the main therapy for NPC. In order to explore the relationship between hsa_circRNA_001387 and radiotherapy, the hsa_circRNA_001387 expression level was detected in 100 patients before and after radiotherapy. The results showed that the expression of hsa_circRNA_001387 in plasma following radiotherapy was significantly higher than that prior to radiotherapy (Figure $3 \mathrm{~A}$ and $\mathrm{B}$ ). Additionally, the relationship of hsa_circRNA_001387 with the response of patients to

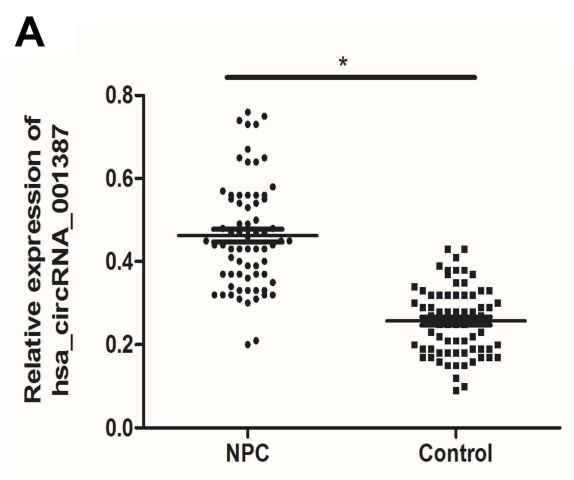

B
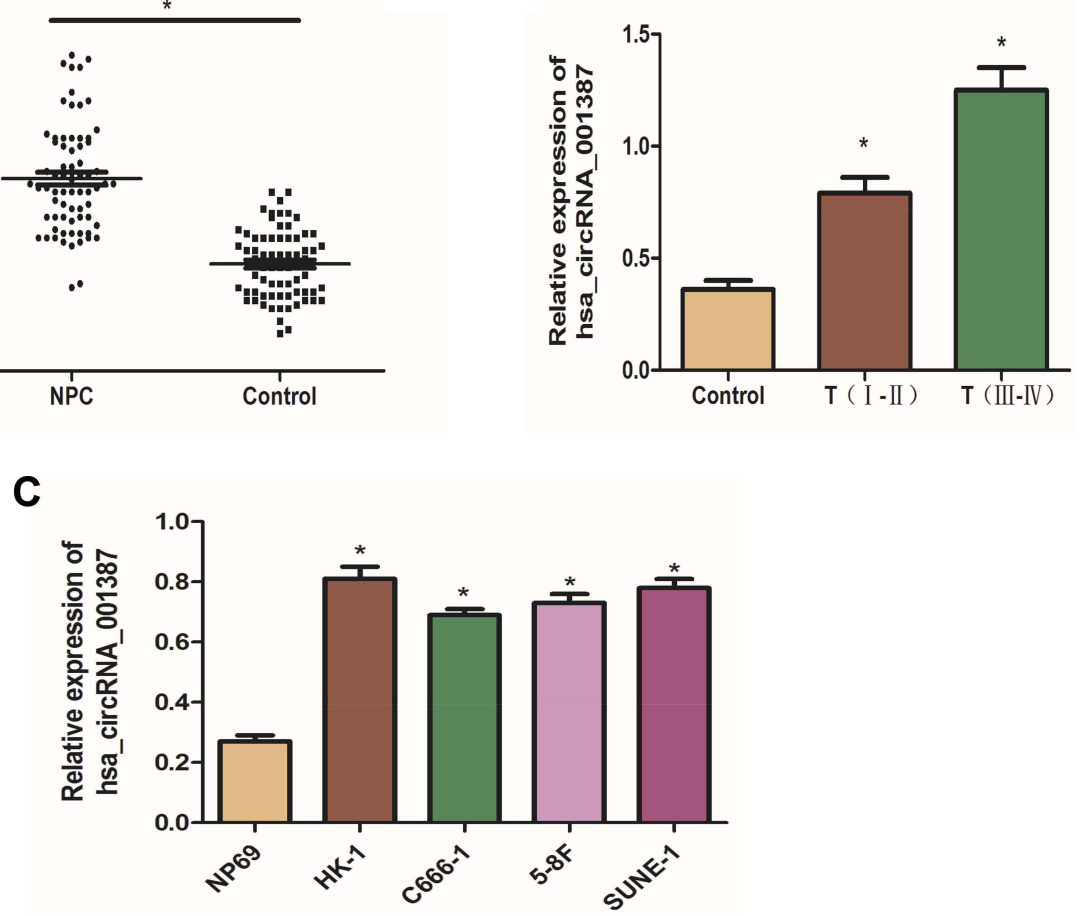

Figure 2 Expression of hsa_circRNA_001387 in NPC patients and NPC cell lines. (A) shows qRT-PCR results of hsa_circRNA_001387. (B and C) show the expression of hsa_circRNA_00 387 in NPC patients at various stages and in various NPC cell lines, respectively. $*$ P $<0.05$, NP69 cells versus control group. All experiments were repeated three times. 

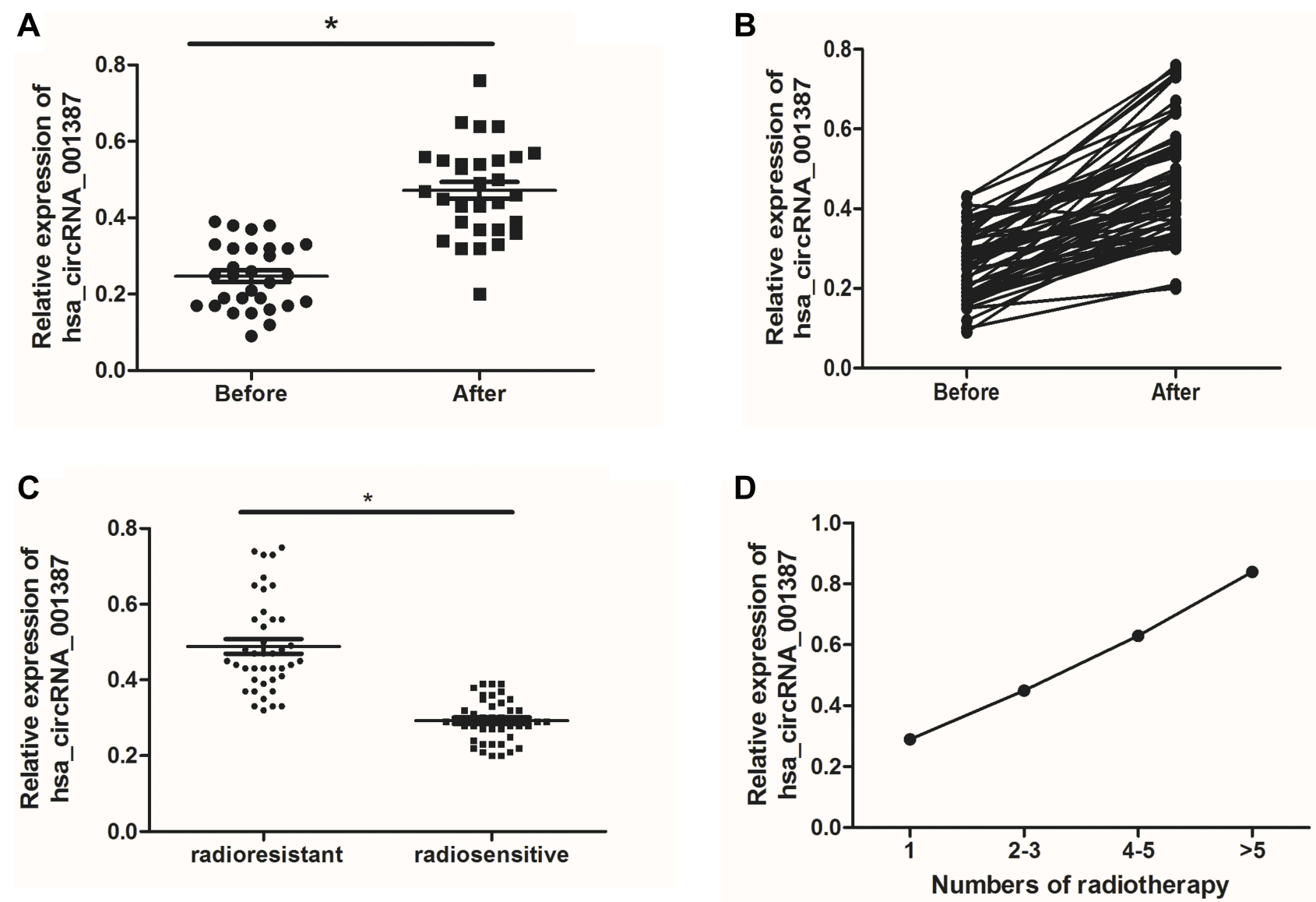

Figure 3 Expression of hsa_circRNA_001387 in NPC patients after radiotherapy. (A and B) show the expression of hsa_circRNA_00 387 in NPC patients before and after radiotherapy, respectively. (C) shows hsa_circRNA_00I387 expression in radio-sensitive and radio-resistant NPC patients. (D) shows hsa_circRNA_00I387 expression in NPC patients after different numbers of radiotherapy. ${ }^{*} p<0.05$, the pre-radiotherapy group versus radiotherapy-sensitive group.

radiotherapy was explored. The results showed that hsa_circRNA_001387 plasma expression was significantly lower in radiosensitive patients than that in radioresistant patients (Figure 3C). The relationship of hsa_circRNA_001387 with radiotherapy was further explored, and the results showed that hsa_circRNA_001387 expression was gradually increased with the increased number of radiotherapy (Figure 3D).

\section{Expression of hsa_circRNA_00I387 Was Correlated with Clinical Symptoms of NPC Patients}

To facilitate the understanding of the clinical value of hsa_circRNA_001387, the correlation of hsa_circRNA_001387 with the pathological characteristics and laboratory indicators of NPC patients was analyzed (Table 3). hsa_circRNA_001387 was shown significantly correlated with tumor differentiation, lymph node metastasis, distant metastasis, TNM staging, EB virus positivity and NPC family history $(\mathrm{P}<0.05)$. In addition, the correlation of hsa_circRNA_001387 with various types of EB antibodies was also analyzed (Table 4 ). The results showed that VCA-IgG and EA-IgA positive patients highly expressed hsa_circRNA_001387, in contrast, VCAIgG and EA-IgA negative patients low expressed hsa_circRNA_001387 $(\mathrm{P}<0.05)$. The expression of NA1-IgA, Zta-IgA and Rta-IgA antibodies was not related to the expression of hsa_circRNA_001387.

\section{Use of hsa_circRNA_00I387 as}

\section{a Diagnostic and Prognostic Marker for NPC}

The ROC curve was plotted to determine the diagnostic value of hsa_circRNA_001387 for NPC patients. As shown in Figure 4A, hsa_circRNA_001387 exhibited high accuracy in the diagnosis of NPC, with an AUC of 0.92 and $\mathrm{P}<0.0001$. This indicated that hsa_circRNA_001387 may be used as 
Table 3 Correlation Between the Clinical Data of 100 NPC Patients and hsa_circRNA_001387 Expression

\begin{tabular}{|c|c|c|c|}
\hline Clinical Data & $\mathbf{N}$ & $\begin{array}{l}\text { hsa_circRNA_00I387 } \\
\text { Expression }\end{array}$ & $P$ value \\
\hline $\begin{array}{l}\text { Age (years) } \\
\quad \geq 50 \\
\quad<50\end{array}$ & $\begin{array}{l}53 \\
47\end{array}$ & $\begin{array}{l}0.788 \pm 0.103 \\
0.683 \pm 0.034\end{array}$ & 0.233 \\
\hline $\begin{array}{l}\text { Gender } \\
\text { Male } \\
\text { Female }\end{array}$ & $\begin{array}{l}59 \\
41\end{array}$ & $\begin{array}{l}0.873 \pm 0.144 \\
0.749 \pm 0.013\end{array}$ & 0.464 \\
\hline $\begin{array}{l}\text { Tumor Size } \\
\begin{array}{l}\geq 3 \mathrm{~cm} \\
<3 \mathrm{~cm}\end{array}\end{array}$ & $\begin{array}{l}42 \\
68\end{array}$ & $\begin{array}{l}0.880 \pm 0.103 \\
0.643 \pm 0.217\end{array}$ & 0.087 \\
\hline $\begin{array}{l}\text { Tumor } \\
\text { Differentiation } \\
\text { High } \\
\text { Moderate } \\
\text { Low }\end{array}$ & $\begin{array}{l}38 \\
26 \\
36\end{array}$ & $\begin{array}{l}0.842 \pm 0.113 \\
0.643 \pm 0.134 \\
0.434 \pm 0.101\end{array}$ & 0.022 \\
\hline $\begin{array}{l}\text { Lymph Node } \\
\text { Metastasis } \\
\text { Yes } \\
\text { No }\end{array}$ & $\begin{array}{l}53 \\
47\end{array}$ & $\begin{array}{l}0.834 \pm 0.073 \\
0.622 \pm 0.068\end{array}$ & 0.033 \\
\hline $\begin{array}{l}\text { Distant } \\
\text { Metastasis } \\
\text { Yes } \\
\text { No }\end{array}$ & $\begin{array}{l}44 \\
56\end{array}$ & $\begin{array}{l}0.643 \pm 0.232 \\
0.553 \pm 0.172\end{array}$ & 0.043 \\
\hline $\begin{array}{l}\text { TNM Staging } \\
\text { Stage I-II } \\
\text { Stage III-IV }\end{array}$ & $\begin{array}{l}58 \\
42\end{array}$ & $\begin{array}{l}0.672 \pm 0.176 \\
0.895 \pm 0.154\end{array}$ & 0.011 \\
\hline $\begin{array}{l}\text { EB Virus } \\
\text { Positive } \\
\text { Negative }\end{array}$ & $\begin{array}{l}62 \\
48\end{array}$ & $\begin{array}{l}0.728 \pm 0.148 \\
0.534 \pm 0.035\end{array}$ & 0.015 \\
\hline $\begin{array}{l}\text { Smoking History } \\
\text { Yes } \\
\text { No }\end{array}$ & $\begin{array}{l}49 \\
51\end{array}$ & $\begin{array}{l}0.655 \pm 0.256 \\
0.549 \pm 0.235\end{array}$ & 0.055 \\
\hline $\begin{array}{l}\text { NPC Family } \\
\text { History } \\
\text { Yes } \\
\text { No }\end{array}$ & $\begin{array}{l}41 \\
59\end{array}$ & $\begin{array}{l}0.843 \pm 0.032 \\
0.654 \pm 0.094\end{array}$ & 0.025 \\
\hline
\end{tabular}

Abbreviations: TNM, tumor-node-metastasis; EB, Epstein-Barr; NPC, nasopharyngeal carcinoma.

a specific and sensitive diagnostic marker. Furthermore, the correlation between hsa_circRNA_001387 and prognosis of the patients was analyzed by survival analysis. It was shown that patients with a high level of hsa_circRNA_001387 exhibited significantly shorter overall survival (OS) and progression-free survival (PFS, Figure 4B and $\mathrm{C}, \mathrm{P}<0.05$ ).
Table 4 EB Virus Antibodies Expression Status Distribution Between Low/High hsa_circ_001387 Expression Groups of NPC Patients

\begin{tabular}{|c|l|l|l|}
\hline Group & $\begin{array}{l}\text { Low } \\
\text { hsa_circ_00I387 } \\
\text { (n=45) }\end{array}$ & $\begin{array}{l}\text { High } \\
\text { hsa_circ_00 I387 } \\
\text { (n=55) }\end{array}$ & P value \\
\hline $\begin{array}{c}\text { VCA-IgA } \\
\text { Positive } \\
\text { Negative }\end{array}$ & 30 & 33 & 0.01 \\
\hline $\begin{array}{c}\text { EA-IgA } \\
\text { Positive } \\
\text { Negative }\end{array}$ & 27 & 22 & 0.02 \\
\hline $\begin{array}{c}\text { NAI-IgA } \\
\text { Positive } \\
\text { Negative }\end{array}$ & 10 & 31 & \\
\hline $\begin{array}{c}\text { Zta-lgA } \\
\text { Positive } \\
\text { Negative }\end{array}$ & 20 & 24 & 0.32 \\
\hline $\begin{array}{c}\text { Rta-lgA } \\
\text { Positive } \\
\text { Negative }\end{array}$ & 22 & 43 & 0.53 \\
\hline
\end{tabular}

Abbreviations: VCA-IgA, IgA antibody to capsid antigen; NAI-IgA, IgA antibody to Epstein-Barr virus nuclear antigen I; EA-IgA, IgA antibody to early antigen; Zta$\lg A$, Zta protein IgA antibody; Rta-lgA, Rta protein IgA antibody.

\section{hsa_circRNA_001387 as an Independent Factor in the Prediction of Prognosis of NPC Patients}

Univariate and multivariate analyses were used to investigate the prognostic factors of NPC patients. Univariate analysis showed that hsa_circRNA_001387 expression, tumor differentiation, lymph node metastasis, distant metastasis, EB virus and TNM staging were significantly correlated with the prognosis of NPC patients (Table 5). Multivariate analysis showed that hsa_circRNA_001387 expression, tumor differentiation, lymph node metastasis, distant metastasis, EB virus and TNM staging were independent factors for the prognosis of NPC patients (Table 5).

\section{Discussion}

NPC is a highly malignant tumor derived from the nasopharyngeal epithelium, with the incidence ranking the first among all head and neck malignancies and the mortality accounting for about $3 \%$ of the total cancer. ${ }^{13}$ The onset of NPC is characterized by geographic region aggregation, ${ }^{14}$ mainly in Southeast Asia, North Africa, and South China. 
A

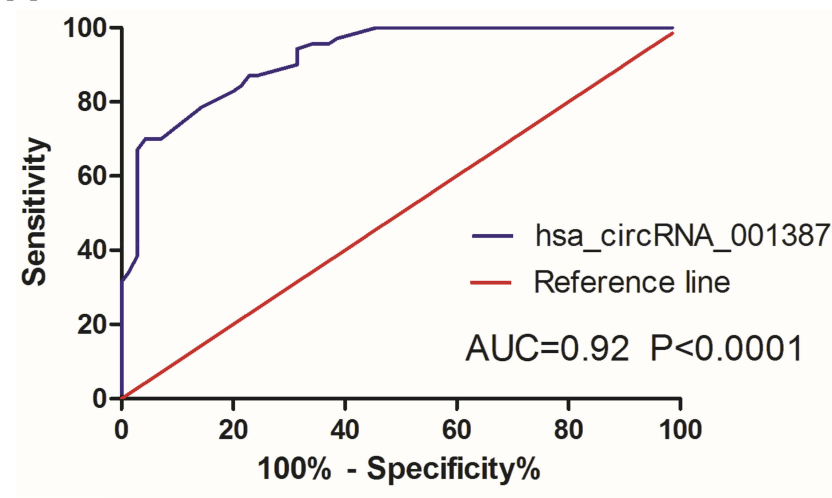

C

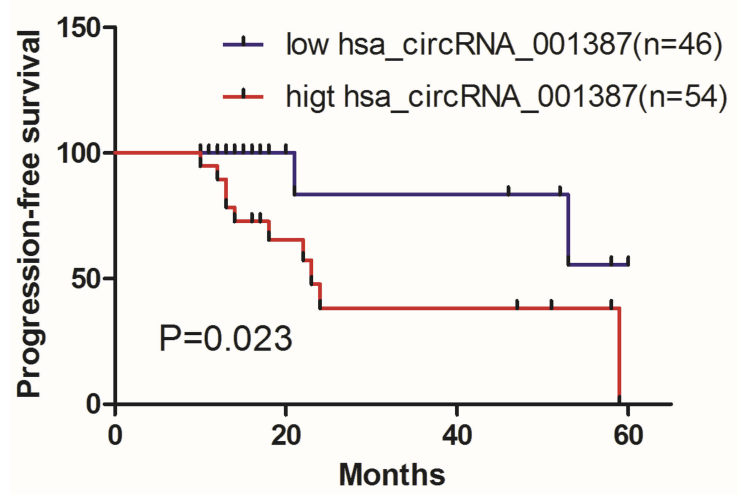

B

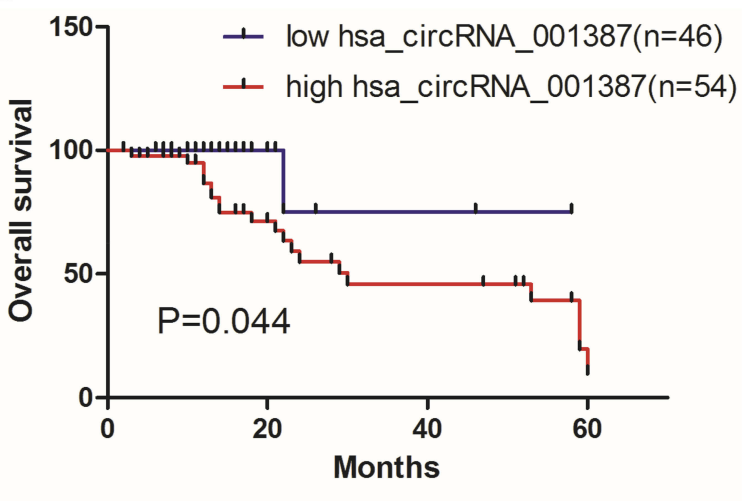

Figure 4 Use of hsa_circRNA_00I387 in the diagnosis and prognosis of NPC patients. (A) shows ROC analysis by hsa_circRNA_00 I 387 in NPC patients. (B and C) show the overall survival and progression-free survival of NPC patients, respectively.

At present, NPC patients are treated mainly by radiotherapy. Supplemented by chemotherapy and surgery, the 5 -year survival rate of NPC patients can be greatly improved. Especially for early NPC patients, the 5-year survival rate can be improved up to $99.5 \% .{ }^{15}$ However, the therapeutic outcomes of patients with advanced cancer remain less ideal. In addition, the frequent local recurrences and distant metastases are still the main reasons for the failure of current nasopharyngeal carcinoma treatment. ${ }^{16,17}$ Early symptoms are often not obvious due to the hidden original lesions. As a result, patients do not visit the hospital for treatment until the middle-late stages. Therefore, finding the effective means for the early diagnosis is of great significance to improve patient survival and to reduce the mortality.

In recent years, with the development of high-throughput sequencing, an increasing number of circRNAs have been found with an important role in the occurrence and development of various diseases and thus can be used as ideal diagnostic and therapeutic biomarkers. ${ }^{18}$ The most in-depth and thorough research between circRNA and diseases is on tumors. ${ }^{19}$ For example, Xi et al reported a variety of abnormally expressed circRNAs in osteosarcoma through circRNA sequencing and bioinformatic analysis, which were closely correlated with osteosarcoma occurrence and development. ${ }^{20}$ Liu and colleagues found that in hepatocellular carcinoma (HCC), circRNA-5692 was upregulated and can be used to predict the prognosis of the patients. ${ }^{21}$ Tian et al showed that hsa_circ_0003159 was downregulated in gastric cancer and that it could be used as a potential cancer marker of gastric cancer patients. ${ }^{22}$ The study of Liu et al showed that circRPMS1 could be a potential therapeutic target for EBV-associated NPC. ${ }^{23} \mathrm{Xu}$ et al found that hsa_circRNA_103827 and hsa_circRNA_000122 can be used as potential prognosis biomarkers and therapeutic targets for squamous cell lung cancer. ${ }^{24}$ Bai et al found that circABCC 2 could be used as a biomarker and therapeutic target in $\mathrm{HCC}^{25}$ These studies demonstrated the potential ability of circRNAs as novel diagnostic biomarkers and therapeutic targets in cancer. In this study we reported the 
Table 5 Univariate and Multivariate Analysis of Prognostic Factors of Patients with Nasopharyngeal Carcinoma

\begin{tabular}{|l|l|l|l|l|}
\hline \multirow{2}{*}{ Variables } & \multicolumn{3}{|l|}{ Univariate Analysis } & \multicolumn{2}{l|}{$\begin{array}{l}\text { Multivariate } \\
\text { Analysis }\end{array}$} \\
\cline { 2 - 5 } & $\begin{array}{l}\text { Hazard } \\
\text { Ratio }\end{array}$ & P value & $\begin{array}{l}\text { Hazard } \\
\text { Ratio }\end{array}$ & P value \\
\hline Age & 1.12 & 0.12 & & \\
Sex & 1.22 & 0.55 & & \\
Tumor size & 1.09 & 0.84 & & \\
Differentiation & 2.95 & 0.03 & 2.54 & 0.01 \\
Lymph node & 2.45 & 0.02 & 2.62 & 0.03 \\
metastasis & & & & \\
Distant metastasis & 2.84 & 0.02 & 2.73 & 0.02 \\
TNM stage & 3.87 & 0.01 & 3.84 & 0.01 \\
EB virus & 2.64 & 0.04 & 2.71 & 0.01 \\
Smoke & 2.12 & 0.08 & & \\
NPC family history & 2.42 & 0.06 & & \\
hsa_circRNA_001387 & 3.45 & 0.01 & 4.35 & 0.01 \\
\hline
\end{tabular}

Abbreviations: TNM, tumor-node-metastasis; EB, Epstein-Barr; NPC, nasopharyngeal carcinoma.

high expression level of hsa_circRNA_001387 in the tumor tissues of NPC patients, indicating that it can be used as a new diagnostic and prognostic marker.

In this study, we first detected NPC tissues by highthroughput circRNA sequencing, and found that there were 50 up-regulated circRNAs and 15 down-regulated circRNAs. Then, we selected three circRNAs with the most significant differences for qRT-PCR verification. The results showed that hsa_circRNA_001387 had significant differences in NPC tissue and control group, while the other two circRNAs had no difference in expression, so we selected hsa_circRNA_001387 for the next study. The circRNA sequencing and qRT-PCR results demonstrated the upregulation of hsa_circRNA_001387 in NPC patients and the value of hsa_circRNA_001387 in the diagnosis and prognosis of NPC patients was investigated. ROC analysis confirmed the high specificity and sensitivity of hsa_circRNA_001387 which could be used as a good diagnostic marker for NPC. In addition, expression of hsa_circRNA_001387 was found significantly correlated with OS and PFS of the patients, indicating that hsa_circRNA_001387 might be used as an important marker of poor prognosis of NPC patients. The above results demonstrated the clinical correlation and important value of hsa_circRNA_001387, which can be used in the early screening for NPC. Lastly, this study also showed that hsa_circRNA_001387 expression was significantly upregulated in stage III/IV patients compared with that in stage
I/II patients, suggesting the possible participation of hsa_circRNA_001387 in NPC development.

Radiotherapy remains the main treatment of NPC. In the early stage of NPC, patients are more sensitive to radiotherapy with a 5-year survival rate of higher than $80 \%{ }^{26}$ Radio-resistance is one of the important reasons of cancer reoccurrence and treatment failure at present. Therefore, improving the sensitivity to radiotherapy is the focus of increasing the chance of successful treatment of NPC. It has been shown that lncRNA ANRIL can reduce the radiosensitivity of NPC by absorbing miR-125a like a sponge. ${ }^{27}$ In addition, the study by Wang showed that miR-24 could increase the radiosensitivity of NPC by directly regulating Jab1/CSN5. ${ }^{28}$ In this research we found that the expression level of hsa_circRNA_001387 in the plasma of radiosensitive NPC patients was significantly lower than that in radioresistant patients, suggesting that hsa_circRNA_001387 may be involved in regulating the radiosensitivity of NPC patients.

In summary, this study reported the expression level of hsa_circRNA_001387 in NPC and demonstrated the value in the diagnosis and prognosis of NPC patients. The results showed that hsa_circRNA_001387 can be used as a good diagnostic and prognostic biomarker of NPC, and that it may influent the radiotherapy efficacy by regulating the radiotherapy sensitivity of NPC patients.

\section{Ethics and Consent Statement}

This study was approved by the Ethics Committee of The Xiangya Hospital of Central South University and the First Affiliated Hospital of Nanchang University. All patients provide written informed consent. Informed consent was obtained from each subject in accordance with the Declaration of Helsinki.

\section{Author Contributions}

All authors contributed to data analysis, drafting and revising the article, gave final approval of the version to be published, and agree to be accountable for all aspects of the work.

\section{Disclosure}

The authors report no declarations of interest.

\section{References}

1. Lin DC, Meng X, Hazawa M, et al. The genomic landscape of nasopharyngeal carcinoma. Nat Genet. 2014;46(8):866-871. doi:10.10 38/ng.3006 
2. Tan WL, Tan EH, Lim DW, et al. Advances in systemic treatment for nasopharyngeal carcinoma. Chin Clin Oncol. 2016;5(2):21. doi:10.21037/cco.2016.03.03

3. Kim BM, Hong Y, Lee S, et al. Therapeutic implications for overcoming radiation resistance in cancer therapy. Int J Mol Sci. 2015;16 (11):26880-26913. doi:10.3390/ijms161125991

4. Prawira A, Oosting SF, Chen TW, et al. Systemic therapies for recurrent or metastatic nasopharyngeal carcinoma: a systematic review. $\mathrm{Br}$ J Cancer. 2017;117(12):1743-1752. doi:10.1038/bjc.2017.357

5. Lee AW, Ma BB, Ng WT, Chan AT. Management of nasopharyngeal carcinoma: current practice and future perspective. J Clin Oncol. 2015;33(29):3356-3364. doi:10.1200/JCO.2015.60.9347

6. Meng S, Zhou H, Feng Z, et al. Circ RNA: functions and properties of a novel potential biomarker for cancer. Mol Cancer. 2017;16 (1):94. doi:10.1186/s12943-017-0663-2

7. Shen F, Liu P, Xu Z, et al. Circ RNA_001569 promotes cell proliferation through absorbing mi R-145 in gastric cancer. $J$ Biochem. 2019;165(1):27-36. doi:10.1093/jb/mvy079

8. Ren S, Xin Z, Xu Y, Xu J, Wang G. Construction and analysis of circular RNA molecular regulatory networks in liver cancer. Cell Cycle. 2017;16 (22):2204-2211. doi:10.1080/15384101.2017.1346754

9. Wang H, Xiao Y, Wu L, Ma D Comprehensive circular RNA profiling reveals the regulatory role of the circ RNA-000911/mi R-449a pathway in breast carcinogenesis. Int J Oncol. 2018;52(3):743-754. doi:10.3892/ijo.2018.4265

10. He JH, Li YG, Han ZP, et al. The Circ RNA-ACAP2/Hsa-mi R-21$5 \mathrm{p} /$ Tiam 1 regulatory feedback circuit affects the proliferation, migration, and invasion of colon cancer SW480 cells. Cell Physiol Biochem. 2018;49(4):1539-1550. doi:10.1159/000493457

11. Chen S, Huang V, Xu X, et al. Widespread and functional RNA circularization in localized prostate cancer. Cell. 2019;176 (4):831-843. doi:10.1016/j.cell.2019.01.025

12. Vo JN, Cieslik M, Zhang Y, et al. The landscape of circular RNA in cancer. Cell. 2019;176(4):869-881. doi:10.1016/j.cell.2018.12.021

13. Bray F, Ferlay J, Soerjomataram I, Siegel RL, Torre LA, Jemal A. Global cancer statistics 2018: GLOBOCAN estimates of incidence and mortality worldwide for 36 cancers in 185 countries. CA Cancer J Clin. 2018;68(6):394-424. doi:10.3322/caac.21492

14. Yu MC, Yuan JM. Epidemiology of nasopharyngeal carcinoma. Semin Cancer Biol. 2002;12(6):421-429. doi:10.1016/S1044579X02000858

15. Pastor M, Lopez PA, Del BE, et al. SEOM clinical guideline in nasopharynx cancer (2017). Clin Transl Oncol. 2018;20(1):84-88. doi:10.1007/s12094-017-1777-0

16. Blanchard P, Lee A, Marguet S, et al. Chemotherapy and radiotherapy in nasopharyngeal carcinoma: an update of the MAC-NPC meta-analysis. Lancet Oncol. 2015;16(6):645-655. doi:10.1016/ S1470-2045(15)70126-9
17. Lee N, Harris J, Garden AS, et al. Intensity-modulated radiation therapy with or without chemotherapy for nasopharyngeal carcinoma: radiation therapy oncology group Phase II trial 0225. J Clin Oncol. 2009;27(22):3684-3690. doi:10.1200/JCO.2008.19.9109

18. Piñero J, Bravo À, Queralt-Rosinach $\mathrm{N}$, et al. DisGeNET: a comprehensive platform integrating information on human disease-associated genes and variants. Nucleic Acids Res. 2017;45 (D1):D833-D839. doi:10.1093/nar/gkw943

19. Dweep H, Sticht C, Pandey P, Gretz N. miRWalk-database: prediction of possible miRNA binding sites by "walking" the genes of three genomes. J Biomed Inf. 2011;44(5):839-847. doi:10.1016/j.jbi.2011. 05.002

20. Xi Y, Fowdur M, Liu Y, et al. Differential expression and bioinformatics analysis of circRNA in osteosarcoma. Biosci Rep. 2019;39(5): BSR20181514. doi:10.1042/BSR20181514

21. Liu Z, Yu Y, Huang Z, et al. CircRNA-5692 inhibits the progression of hepatocellular carcinoma by sponging miR-328-5p to enhance DAB2IP expression. Cell Death Dis. 2019;10(12):900. doi:10.1038/ s41419-019-2089-9

22. Tian M, Chen R, Li T, Xiao B. Reduced expression of circRNA hsa_circ_0003159 in gastric cancer and its clinical significance. J Clin Lab Anal. 2018;32(3):e22281. doi:10.1002/jcla.22281

23. Liu Q, Shuai M, Xia Y. Knockdown of EBV-encoded circRNA circRPMS1 suppresses nasopharyngeal carcinoma cell proliferation and metastasis through sponging multiple miRNAs. Cancer Manag Res. 2019;11(5):8023-8031. doi:10.2147/CMAR.S218967

24. $\mathrm{Xu} \mathrm{J}$, Shu Y, Xu T, et al. Microarray expression profiling and bioinform- atics analysis of circular RNA expression in lungsquamous cell carcinoma. Am J Transl Res. 2018;10(3):771-783.

25. Bai N, Peng E, Xia F, Wang D, Li X, Li X. CircABCC2 regulates hepatocellular cancer progression by decoying MiR-665. J Cancer. 2019;10(17):3893-3898. doi:10.7150/jca.31362

26. Zhang L, Yang L, Li JJ, Sun L. Potential use of nucleic acid-based agents in the sensitization of nasopharyngeal carcinoma to radiotherapy. Cancer Lett. 2012;323(1):1-10. doi:10.1016/j.canlet.20 12.03 .030

27. Hu X, Jiang H, Jiang X. Downregulation of lncRNA ANRIL inhibits proliferation, induces apoptosis, and enhances radiosensitivity in nasopharyngeal carcinoma cells through regulating miR-125a. Cancer Biol Ther. 2017;18(5):331-338. doi:10.1080/15384047.20 17.1310348

28. Wang S, Pan Y, Zhang R, et al. Hsa-miR-24-3p increases nasopharyngeal carcinoma radiosensitivity by targeting both the 3 'UTR and 5'UTR of Jab1/CSN5. Oncogene. 2016;35(47):6096-6108. doi:10.10 38/onc. 2016.147
OncoTargets and Therapy

\section{Publish your work in this journal}

OncoTargets and Therapy is an international, peer-reviewed, open access journal focusing on the pathological basis of all cancers, potential targets for therapy and treatment protocols employed to improve the management of cancer patients. The journal also focuses on the impact of management programs and new therapeutic agents and protocols on patient perspectives such as quality of life, adherence and satisfaction. The manuscript management system is completely online and includes a very quick and fair peer-review system, which is all easy to use. Visit http://www.dovepress.com/ testimonials.php to read real quotes from published authors. 